\title{
Autoeficácia na Formação Superior: Percepções Durante o Primeiro Ano de Graduação
}

Freshman's Self-Efficacy In Undergraduation

Auto-Eficacia en La Formación Superior: Percepciones Durante el Primer Año de Graduación

Daniela Couto

Guerreiro-Casanova \&

Soely Aparecida Jorge

Polydoro

Universidade

Estadual de Campinas

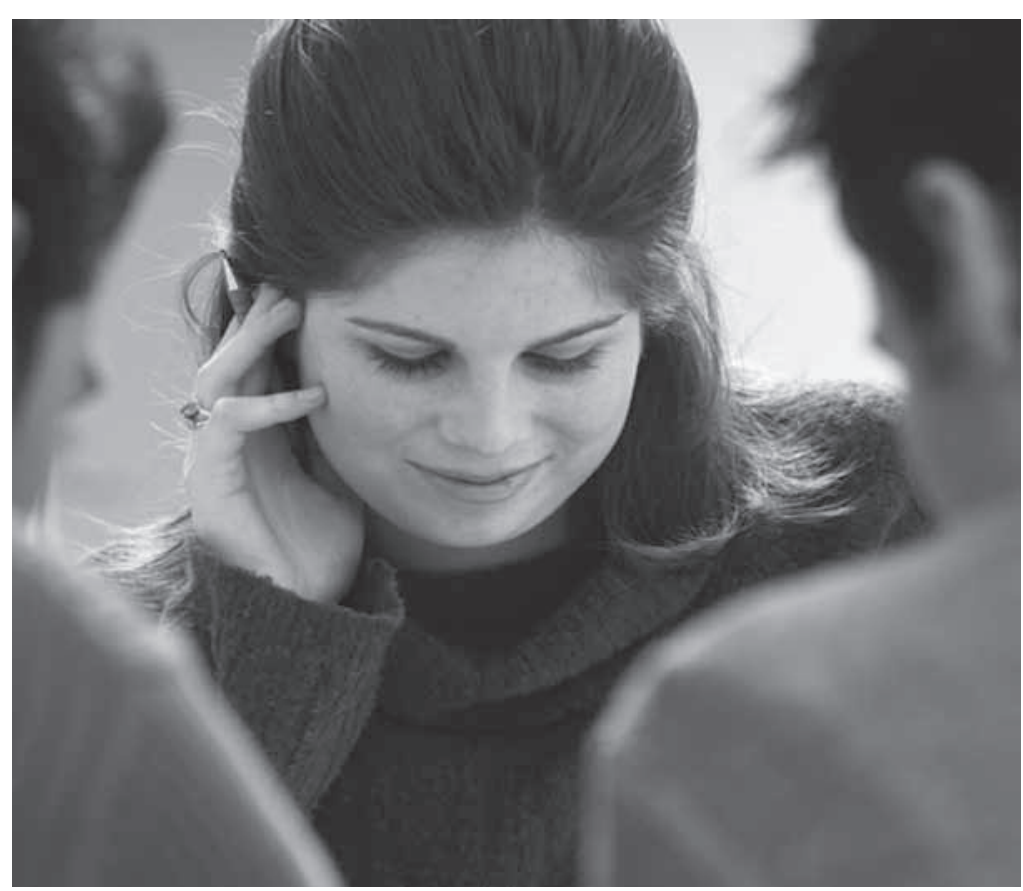


Resumo: Autoeficácia na formação superior é entendida como a crença de um estudante em sua capacidade de organizar e executar cursos de ações requeridas para produzir certas realizações referentes aos aspectos compreendidos pelas tarefas acadêmicas pertinentes ao ensino superior. Com o objetivo de comparar a autoeficácia na formação superior entre o primeiro e o segundo períodos letivos, realizou-se esta pesquisa com 189 ingressantes em Letras, Matemática, Administração e Tecnologia da Informação de uma instituição privada do ensino superior. Por meio da escala Autoeficácia na Formação Superior, encontrou-se diferença negativa significante $(z=-3,292, p=0,001)$ em relação às médias de cada período. Os resultados foram discutidos à luz da teoria social cognitiva. Foram destacadas possibilidades de intervenção e de pesquisas futuras.

Palavras-chave: Autoeficácia. Estudantes universitários. Ensino superior. Teoria social cognitiva.

Abstract: Perceived self-efficacy in undergraduation is a construct of a student's belief in his/her capacity to organize and carry out the actions required to realize certain achievements in academic tasks in undergraduation. The research, comprised of 189 participants, is aimed at comparing perceived self-efficacy in undergraduation between first and second semesters freshmen. Using the Higher Education Self-efficacy Scale, was found negative with significant difference $(z=-3,292, p=0,001)$ between each term. The results were analised according to the social cognitive theory. Suggestions for future intervention and research were highlighted.

Keywords: Self-efficacy. Freshman students. Higher education. Social cognitive theory.

Resumen: Auto-eficacia en la formación superior es entendida como la creencia de un estudiante en su capacidad de organizar y ejecutar cursos de acciones requeridas para producir ciertas realizaciones referentes a los aspectos comprendidos por las tareas académicas pertinentes a la enseñanza superior. Con el objetivo de comparar la auto-eficacia en la formación superior entre el primero y el segundo períodos lectivos, se realizó esta pesquisa con 189 ingresantes en Letras, Matemáticas, Administración y Tecnología de la Información de una institución privada de la enseñanza superior. Por medio de la escala Auto-eficacia en la Formación Superior, se encontró diferencia negativa significante $(z=-3,292, p=0,001)$ en relación a las medias de cada período. Los resultados fueron discutidos a la luz de la teoría social cognitiva. Fueron destacadas posibilidades de intervención y de pesquisas futuras.

Palabras clave: Auto-eficacia. Estudiante universitario. Educacion superior. Teoría social cognitiva.

A crescente democratização do acesso à educação superior, por si só, não garante o sucesso do estudante nesse nível educacional (Astin, 1993). Há o cuidado de se evitar a massificação, na qual o ensino é proporcionado a todos de modo semelhante, e de favorecer o acesso que possibilite a permanência e o resultado positivo para o estudante. Diante disso, entender que o início da frequência a um curso de nível superior se caracteriza como um processo de transição-integração a esse nível de ensino, no qual o estudante ingressante necessita perceber-se capaz de autodirecionar sua aprendizagem, é uma complexa atribuição para os educadores que nele atuam, seja na docência, seja no serviço de apoio aos estudantes ou na política educacional (Albiero-Walton, 2003; Astin, 1993; Dias \& Azevedo, 2001; Jakubowsi \& Dembo, 2004).
A literatura da área relata a questão do desempenho na educação básica como um aspecto condicional dos estudantes. Nesse sentido, quanto melhor o desempenho obtido na educação básica, melhor seria a predição de integração ao ensino superior (Astin, 1993; Pascarella \& Terezini, 2005). Tal conceito de integração pode ser compreendido como uma referência pela qual o indivíduo compartilha das atitudes normativas e dos valores dos colegas e do corpo docente da instituição, respeitando as exigências formais e informais da instituição, da comunidade acadêmica e dos subgrupos dos quais faz parte justamente para fazer parte, ou seja, para integrá-lo. Esse processo se caracteriza por reunir a dinâmica relação entre o estudante e as vivências acadêmicas, que envolve os aspectos ambientais e os aspectos internos ao estudante (Pascarella \& Terenzini, 2005). No entanto, 
Segundo a teoria social cognitiva (Bandura, 1997, p.03), a crença de autoeficácia se refere a

"crenças de

alguém em sua

capacidade

de organizar

e executar

cursos de ações requeridas para produzir certas realizações", influenciando o modo como as pessoas se sentem, pensam, são motivadas e se comportam. as dificuldades de integração também têm sido evidenciadas tanto em estudantes que possuem um bom repertório de ingresso, com experiências bem sucedidas de formação acadêmica no nível de ensino médio, quanto em estudantes que construíram, no decorrer da vida escolar, um repertório de ingresso mínimo (Albiero-Walton, 2003; Hirose, Wada, \& Watanabe, 1999; Jakubowski \& Dembo, 2004). Um dos enfoques dedicados à discussão dessa informação é representado pelo entendimento do constructo da crença de autoeficácia na formação superior (AlbieroWalton, 2003; Dias \& Azevedo, 2001; Jakubowski \& Dembo, 2004; Lent, Taveira, Sheu, \& Singley, 2009; Oliveira \& Simões, 2000).

Segundo a teoria social cognitiva (Bandura, 1997, p.03), a crença de autoeficácia se refere a "crenças de alguém em sua capacidade de organizar e executar cursos de ações requeridas para produzir certas realizações", influenciando o modo como as pessoas se sentem, pensam, são motivadas e se comportam. No entanto, o constructo da autoeficácia requer um entendimento referente aos diversos domínios incluídos nas ações humanas. Uma pessoa pode ter, por exemplo, uma forte crença de autoeficácia acadêmica, julgando ser capaz de organizar e executar cursos de ações requeridas para produzir certas realizações referentes aos aspectos intelectuais e de aprendizagem, mas ter uma fraca crença de autoeficácia social, pois julga-se incapaz de estabelecer boas relações sociais com seus pares. Em cada domínio, a crença de autoeficácia pode ser analisada em relação à sua intensidade, relativa à força da convicção, de modo que crenças de autoeficácia frágeis são facilmente desconstruídas por situações de fracassos, sendo que uma crença de autoeficácia forte se mantém frente a uma situação de insucesso e também pode ser analisada em relação à magnitude da crença, que se refere à amplitude da crença de eficácia, ao tamanho da dificuldade que a pessoa acredita poder superar em determinado domínio. Além disso, a crença de autoeficácia também pode ser analisada em relação à generalidade da mesma, de modo a compreender as diversas tarefas ou aspectos que compõem o domínio autoeficácia na formação superior neste caso pesquisado.

É necessário compreender que as crenças de autoeficácia são construídas ao longo da vida. Esse processo é desenvolvido pela interação triádica entre os aspectos pessoais, comportamentais e sociais. Desse modo, por meio da reciprocidade triádica, a crença de autoeficácia é construída com informações de quatro fontes: (1) experiência direta: essa é a fonte de autoeficácia de maior influência na construção da crença, pois baseia-se em resultados das próprias experiências. Os bons resultados tendem a fortalecer a crença de autoeficácia e a elevar as expectativas, além de possibilitar a generalização do sucesso percebido para situações semelhantes; (2) experiência vicária: uma das habilidades do ser humano é aprender com as experiências de outras pessoas. Essa afirmação se aplica ao conteúdo histórico e social produzido pela humanidade bem como às expectativas estabelecidas por meio da comparação social; (3) persuasão social: é uma das fontes de autoeficácia mais utilizada. No entanto, sua influência na construção dessa crença é uma das menos evidenciadas, pois não promove uma experiência autêntica, vivida pela própria pessoa. Apesar disso, sabe-se que aquele que participa de um ambiente social que promova a percepção de que se é capaz de resolver as situações difíceis irá despender mais esforço para resolver dadas situações; (4) estado físico e emocional: são derivados de processos cognitivos, nos quais o efeito da decodificação das informações e a motivação gerada pela ansiedade e pela excitação são tratados como interdependentes. Conforme as circunstâncias, a ansiedade e o estresse, bem como o sono e o cansaço físico, levam 
ao entendimento de um fraco julgamento da capacidade e da competência frente a determinada situação, o que denota uma baixa crença de autoeficácia, sendo o contrário verdadeiro (Bandura, 1997, 2004).

Apesar de a literatura geralmente utilizar o termo autoeficácia acadêmica para referir-se tanto à crença do educando da educação básica quanto à crença do estudante do ensino superior, neste relato, como explicado posteriormente, decidiu-se utilizar a expressão autoeficácia na formação superior para referir-se à crença dos estudantes nesse nível de ensino. O primeiro estudo sobre autoeficácia do estudante do ensino superior, realizado por Bandura e Cervone (1983), pesquisou a relação entre esse constructo e a autoavaliação do estudante. O objetivo dessa pesquisa era testar a hipótese de que a autoavaliação e a autoeficácia acadêmica atuavam como mecanismos mediadores para o estabelecimento de objetivos e de motivação para performance. Esse estudo teve uma amostra formada por 45 estudantes do sexo masculino e 45 estudantes do sexo feminino, e verificou-se que, quando havia a presença de feedback sobre a performance dos estudantes e sobre o nível em que eles estavam, a autoavaliação e a autoeficácia influenciavam a magnitude da motivação dos estudantes. Já o segundo relato de pesquisa, conduzido por Bandura e Cervone (1986), visou a identificar as diferentes influências dos mecanismos autorreativos, como a autoavaliação, o autoestabelecimento de objetivos e a autoeficácia, na motivação dos estudantes. Com uma amostra formada por 88 estudantes, essa pesquisa descritiva identificou que a autoeficácia percebida contribui para a motivação do estudante do ensino superior em um vasto número de condições discrepantes, que a autoavaliação influenciava a motivação apenas quando a discrepância em nível comparativo era moderada e que o estabelecimento de objetivos influenciava a motivação em quase todos os níveis de comparação, menos quando a discrepância em nível comparativo era grande.

No âmbito do ensino superior, Cole e Denzine (2004) realizaram um estudo com 164 estudantes entre 17 e 21 anos, dos quais $27 \%$ eram estudantes ingressantes. Como resultado, demonstraram que: (1) o constructo da autoeficácia na formação superior está fortemente correlacionado com a motivação do estudante, (2) há a presença de relação positiva entre autoeficácia na formação superior e o controle da aprendizagem percebida e o valor atribuído a determinada tarefa bem como a sua ação mediadora entre os processos motivacionais e de resultados potencialmente esperados, (3) existe diferença entre autoeficácia na formação superior e otimismo, de modo que os estudantes classificados como otimistas evidenciaram baixo controle sobre a aprendizagem percebida e o valor atribuído ao conteúdo do curso, e que (4) a autoestima desempenha importância mínima na motivação do estudante para realizar determinada tarefa educacional.

Já Byer (2001) destaca a importância dos docentes para a crença de autoeficácia na formação superior, isso porque essa crença é desenvolvida por meio da influência das mensagens recebidas ou não, que são provenientes dos docentes. Além disso, a pesquisa por ele realizada, da qual participaram 102 estudantes americanos, indicou correlações da variável dependente autoeficácia na formação superior com o envolvimento $(r=0,55 ; p<0,01)$ dos estudantes nas experiências acadêmicas, com o conhecimento $(r=0,35 ; p<0,01)$ construído durante o curso, com a habilidade de pensamento superior $(r=0,37 ; p<0,01)$ e com a habilidade profissional $(r=0,36$; $p$ $<0,01)$ apresentadas pelos estudantes, de modo que essas variáveis independentes explicaram $32 \%$ da variância $(p<0,01)$ 
na autoeficácia na formação superior dos estudantes pesquisados, por meio da análise de correlação múltipla.

Nesse sentido, Dias e Azevedo (2001) identificaram que a autoeficácia na formação superior é determinante para o rendimento acadêmico. Esse estudo, realizado por meio de equação estrutural, contou com 714 estudantes, dos quais 418 eram ingressantes, e nele foram encontradas evidências de que a persistência parece afetar o rendimento acadêmico indiretamente por meio do seu efeito na autoeficácia na formação superior. A relação da crença de autoeficácia na formação superior como mediadora da autorregulação acadêmica foi evidenciada no estudo realizado por Jakubowsi e Dembo (2004). Nesse estudo, os 210 participantes eram estudantes de uma universidade privada americana. Esses estudantes ingressaram na universidade com matrícula condicionada à frequência ao módulo de estratégias de aprendizagem e de estudo, pois a média obtida ao término do ensino médio, que garante o acesso à educação superior, foi a mínima possível. Por meio da análise de regressão, Jakubowsi e Dembo (2004) identificaram que a crença de autoeficácia na formação superior, isoladamente, explica significativamente $9 \%$ do comportamento acadêmico dos estudantes, porém a crença de autoeficácia na formação superior associada à autorregulação explica significativamente (de $18 \%$ a $27 \%$ ) o comportamento acadêmico do estudante. Esse estudo destacou a importância de se conhecer o modo como a autoeficácia na formação superior e a autorregulação são construídas para que as práticas de intervenções pedagógicas, como o módulo de estratégias de aprendizagem e de estudo, possam auxiliar os estudantes de forma mais eficiente.

Ainda em relação aos estudantes que possuem dificuldades de aprendizagem, StallworthClark, Nolen, Warketin e Scott (2000) identificaram que a crença de autoeficácia na formação superior está significantemente correlacionada à performance obtida no curso. Esses pesquisadores dividiram a amostra pesquisada em três grupos, sendo: (1) estudantes com dificuldades de aprendizagem, que apresentaram correlação da autoeficácia na formação superior com o desempenho demonstrado no curso ( $r=0,79$; $p<0,0001)$, (2) estudantes com dificuldades de aprendizagem que frequentavam uma oficina de estratégia de aprendizagem a fim de remediar a situação acadêmica e que também apresentaram correlação da autoeficácia na formação superior com o desempenho no curso $(r=0,64 ; p<$ 0,0001), e (3) estudantes sem dificuldades de aprendizagem que demonstraram menor correlação da autoeficácia na formação superior com o desempenho $(r=0,48 ; p<$ 0,0001). No entanto, a pesquisa realizada por Albiero-Walton (2003) demonstrou que os estudantes com melhores desempenhos e sem dificuldades de aprendizagem apresentam também maiores níveis de autoeficácia na formação superior, de persistência, de motivação e de integração. Esses estudos reforçam a necessidade de se compreender os mecanismos relacionados à construção da autoeficácia na formação superior e suas implicações nas vivências acadêmicas, a fim de elaborar as intervenções educativas pertinentes a cada instituição e/ou grupo de estudantes (Stallworth-Clark et al., 2000; Albiero-Walton, 2003).

Ao verificar a autoeficácia de formação superior em relação ao gênero, os estudos têm demonstrado que não existem diferenças significativas entre homens e mulheres (Hirose et al., 1999; Oliveira \& Simões, 2001). No entanto, quando o estudo é realizado com estudantes do ensino superior que apresentam distúrbios de aprendizagem, foi encontrado um índice menor de crença de autoeficácia na formação superior para as mulheres (AlbieroWalton, 2003). Esse dado foi atribuído à 
diferença cultural da educação feminina, que algumas vezes dissemina a idéia de que a mulher é menos capaz do que o homem. Além disso, foi verificado que as mulheres indicam menor autoeficácia para pensamento lógico e argumentativo, o que pode ser um empecilho para o desempenho acadêmico e profissional em algumas áreas, todavia apresentam maiores índices de autoeficácia para o relacionamento interpessoal do que os homens (Hirose et al., 1999).

Já os estudantes de mais idade, com vasta experiência educacional e conhecimento das próprias habilidades e das próprias fragilidades, têm demonstrado crença mais forte de autoeficácia na formação superior se comparados com estudantes mais jovens, mesmo que com modesta diferença (Dias \& Azevedo, 2001; Oliveira \& Simões, 2001). Ainda em relação às variáveis condicionais dos estudantes, ou seja, em relação às características específicas dos estudantes, como idade, gênero e histórico educacional, entre outras, Zajacova, Lynch e Espenshade (2005) realizaram uma pesquisa considerando as variáveis condicionais dos estudantes e o estresse. Nesta foi possível identificar que o estresse explica a variância da permanência no ensino superior (9\%), a variância da quantidade de créditos cursados (10\%) e a variância no desempenho (23\%). Já considerando os aspectos condicionais e a autoeficácia na formação superior, encontrouse a explicação da variância a $6 \%$ em relação à permanência no ensino superior, $14 \%$ da variância nos créditos e 32\% da variância no desempenho. De acordo com os dados expostos, percebe-se que a autoeficácia na formação superior explica melhor do que o estresse a performance obtida nos créditos cursados e no desempenho acadêmico, sendo mais importante para predizê-los. No entanto, o estresse explica melhor a permanência ou não, no ensino superior, do que a autoeficácia na formação superior.
Pelo exposto, pode-se perceber que autoeficácia na formação superior apresentase como um importante constructo para as experiências universitárias. Nesse sentido, entende-se que o ensino superior constitui domínio específico de autoeficácia devido às características e às experiências próprias a tal nível de ensino. Assim, o constructo envolve a amplitude das vivências e demandas características da experiência no ensino superior e, como tal, passa a ser definida, no presente estudo, como as crenças de um estudante em sua capacidade de organizar e de executar cursos de ações requeridas para produzir certas realizações referentes aos aspectos compreendidos pelas tarefas acadêmicas pertinentes ao ensino superior.

Apesar da constatação de sua importância no âmbito internacional, o conhecimento sobre a autoeficácia na formação superior ainda é incipiente na realidade nacional. Entende-se que, se for bem compreendida, pode auxiliar os docentes, os profissionais que atuam em serviços de apoio ao estudante e as equipes de gestão das instituições de ensino superior a desenvolver ações educacionais que promovam o seu fortalecimento. Diante da importância de obtenção desse conhecimento, esta investigação buscou comparar a relação entre a autoeficácia de formação superior de estudantes entre o primeiro e o segundo semestres do curso.

\section{Método}

\section{Participantes}

A primeira fase contou com 332 estudantes ingressantes. Já a segunda fase foi composta por 221 estudantes. Cabe esclarecer que todos os participantes ingressaram no início do ano letivo de 2006. Como o objetivo geral desta pesquisa implica a análise das mudanças ocorridas no primeiro ano do curso, fez-se necessária a utilização de amostra pareada, de modo a garantir que todos os estudantes 
aqui analisados tenham participado dos dois momentos de coleta de dados. Desse modo, a amostra pareada final desta pesquisa foi composta por 189 estudantes ingressantes nos cursos de Letras, Matemática, Informática e Administração de Empresas, dos quais 85 (45\%) eram do gênero masculino e 104 (55\%) do gênero feminino. Em relação à faixa etária, pôde-se verificar que 71 (37,6\%) estudantes estavam incluídos na faixa etária tradicional (até 21 anos), 44 (23,3\%) pertenciam à faixa dos 22 a 25 anos e $74(39,2 \%)$ à faixa etária não tradicional (acima de 26 anos). A idade média desses participantes foi 25,73 anos ( $\mathrm{dp}=7,777)$. A maioria da amostra era proveniente de instituições públicas de ensino tanto no ensino fundamental ( $n=175 ; 93,6 \%)$ quanto no ensino médio ( $n=166 ; 91,2 \%$ ), e foi composta por estudantes de primeira geração $(77,8 \%$ ), definidos como estudantes cujo pai/mãe não possuem experiência no ensino superior, mesmo incompleta. A maioria $(n=153 ; 81 \%)$ dos participantes deste estudo era matriculada no período noturno. Esse dado provavelmente está relacionado ao oferecimento dos cursos, uma vez que há mais cursos no período noturno, e ao fato de que $160(84,7 \%)$ estudantes trabalhavam. Ressalta-se que a amostra foi escolhida de modo intencional e por conveniência.

\section{Instrumento de coleta de dados}

Para cada fase deste estudo, foram utilizados um Termo de Consentimento Livre e Esclarecido, um questionário de caracterização e a Escala de Autoeficácia na Formação Superior (Polydoro \& Guerreiro-Casanova, 2010).

A Escala Autoeficácia na Formação Superior - AEFS - (Polydoro \& Guerreiro-Casanova, no prelo) é composta por 32 itens, que verificam a percepção do estudante em relação à capacidade referente aos diversos aspectos que compõem as experiências no ensino superior, conforme descrição apresentada na Tabela 1. As percepções podem variar em likert de 10 pontos, de modo que o valor 1 corresponde a pouco capaz e o valor 10, a muito capaz.

Tabela 1. Descrição das dimensões da Escala de Autoeficácia na Formação Superior e seus índices psicométricos

\begin{tabular}{|c|c|c|c|c|}
\hline Dimensão & Descrição & Exemplos de itens & Alpha & Variância \\
\hline $\begin{array}{l}\text { Autoeficácia } \\
\text { acadêmica }\end{array}$ & $\begin{array}{l}\text { Confiança percebida na capacidade } \\
\text { de aprender, demonstrar e aplicar o } \\
\text { conteúdo do curso }\end{array}$ & $\begin{array}{l}\text { Quanto eu sou capaz } \\
\text { de aprender os } \\
\text { conteúdos que são } \\
\text { necessários à minha } \\
\text { formação? }\end{array}$ & 0,881 & $37,874 \%$ \\
\hline $\begin{array}{l}\text { Autoeficácia na } \\
\text { regulação da } \\
\text { formação }\end{array}$ & $\begin{array}{l}\text { Confiança percebida na capacidade } \\
\text { de estabelecer metas, fazer escolhas, } \\
\text { planejar e autorregular suas } \\
\text { ações no processo de formação e } \\
\text { desenvolvimento de carreira }\end{array}$ & $\begin{array}{l}\text { Quanto eu sou capaz } \\
\text { de planejar ações para } \\
\text { atingir minhas metas } \\
\text { profissionais? }\end{array}$ & 0,871 & $6,158 \%$ \\
\hline $\begin{array}{l}\text { Autoeficácia na } \\
\text { interação social }\end{array}$ & $\begin{array}{l}\text { Confiança percebida na capacidade } \\
\text { de relacionar-se com os colegas e } \\
\text { professores com fins acadêmicos e } \\
\text { sociais }\end{array}$ & $\begin{array}{l}\text { Quanto eu sou capaz } \\
\text { de pedir ajuda, quando } \\
\text { necessário, aos colegas } \\
\text { nas atividades do } \\
\text { curso? }\end{array}$ & 0,800 & $4,853 \%$ \\
\hline
\end{tabular}




\begin{tabular}{|c|c|c|c|c|}
\hline Dimensão & Descrição & Exemplos de itens & Alpha & Variância \\
\hline $\begin{array}{l}\text { Autoeficácia em } \\
\text { ações pró-ativas }\end{array}$ & $\begin{array}{l}\text { Confiança percebida na capacidade } \\
\text { de aproveitar as oportunidades de } \\
\text { formação, atualizar os conhecimentos e } \\
\text { promover melhorias institucionais }\end{array}$ & $\begin{array}{l}\text { Quanto eu sou } \\
\text { capaz de reivindicar } \\
\text { atividades } \\
\text { extracurriculares } \\
\text { relevantes para minha } \\
\text { formação? }\end{array}$ & 0,852 & $4,264 \%$ \\
\hline $\begin{array}{l}\text { Autoeficácia na } \\
\text { gestão acadêmica }\end{array}$ & $\begin{array}{l}\text { Confiança percebida na capacidade de } \\
\text { envolver-se, planejar e cumprir prazos } \\
\text { em relação às atividades acadêmicas }\end{array}$ & $\begin{array}{l}\text { Quanto eu sou capaz } \\
\text { de esforçar-me nas } \\
\text { atividades acadêmicas? }\end{array}$ & 0,803 & $3,537 \%$ \\
\hline
\end{tabular}

Os dados demonstrados na Tabela 1 foram obtidos por meio da análise fatorial exploratória, com extração de fatores principais e rotação varimax, utilizando-se o software estatístico SPSS 13. Além disso, a consistência interna total da escala é de 0,948, sendo 56,687\% a explicação da variância sobre a autoeficácia na formação superior, dados que evidenciam a adequação do instrumento para a mensuração desse constructo (Polydoro \& Guerreiro, 2010).

\section{Procedimentos de pesquisa}

Foi realizada uma pesquisa de tipo descritiva com delineamento correlacional e caráter longitudinal, composta por duas fases de coleta, uma realizada em abril e a outra, em outubro de 2006. Essa estrutura temporal permitiu verificar a percepção dos estudantes próxima ao ingresso no curso de graduação e também após a vivência de várias atividades acadêmicas, tais como aulas com professores diversos, seminários, provas e encerramento do primeiro semestre letivo e início do próximo.

O projeto de pesquisa obteve parecer favorável pela Comissão de Ética em Pesquisa (CAAE 0176.0.000.146-06). A pesquisa foi realizada em uma instituição privada localizada na região metropolitana de São Paulo que, usualmente, atende estudantes acima dos 22 anos de idade vindos de bairros periféricos. Os dados foram obtidos coletivamente em sala de aula dos diferentes cursos, em disciplinas tipicamente frequentadas pelos estudantes ingressantes. No início da coleta, foi realizada uma explicação para todos os estudantes sobre os objetivos da pesquisa, esclarecendo que a participação era voluntária e garantido o sigilo sobre as informações obtidas.

As análises estatísticas foram executadas com a utilização do software Statistical Package for Social Science (SPSS 13.0). Como os dados se caracterizaram como não paramétricos, foi utilizado o teste Wilconxon para a comparação entre a autoeficácia na formação superior da $1 \underline{\underline{a}}$ e $2 \underline{\underline{a}}$ fases.

\section{Resultados}

Ao comparar os dados obtidos na 1ㅜ; ; e na $2^{2}$ a fases, percebe-se que há uma diferença significante em relação às médias obtidas sobre autoeficácia na formação superior nas $1 \underline{a}$ e na $2^{\underline{a}}$ fase $(z$ 
$=-3,292$, com $p=0,001$ ), como pode ser observado na Tabela 2. Esses resultados podem indicar que, após a frequência ao ensino superior, ao longo do período pesquisado, a percepção da autoeficácia na formação superior diminuiu para 96 estudantes (média rank $=78,44$ ) e intensificou-se para 55 estudantes (média rank $=71,75$ ).

Tabela 2. Relação entre autoeficácia na formação superior da 1 ạ fase e da $2 \underline{\underline{a}}$ fase dos estudantes ingressantes

\begin{tabular}{|c|c|c|c|c|c|c|c|}
\hline \multicolumn{2}{|l|}{ Dimensões } & $\mathbf{n}$ & $\begin{array}{l}\text { Média } \\
\text { rank }\end{array}$ & $\mathrm{Z}$ & Sig. & \multicolumn{2}{|c|}{$\begin{array}{l}\text { Média } \\
\text { descritiva }\end{array}$} \\
\hline Autoeficácia em ações & Negativo & 111 & 84,19 & $-3,896$ & $0,000^{*}$ & 1 a fase & 7,61 \\
\hline \multirow[t]{3}{*}{ pró-ativas I e II } & Positivo & 55 & 82,11 & & & $2^{\mathrm{a}}$ fase & 7,24 \\
\hline & Igual & 9 & & & & & \\
\hline & Total & 175 & & & & & \\
\hline Autoeficácia acadêmica & Negativo & 90 & 83,12 & $-1,472$ & 0,141 & 1 a fase & 7,94 \\
\hline \multirow[t]{3}{*}{ Iell } & Positivo & 72 & 79,47 & & & $2 \underline{a}$ fase & 7,82 \\
\hline & Igual & 16 & & & & & \\
\hline & Total & 178 & & & & & \\
\hline Autoeficácia na & Negativo & 110 & 81,83 & $-4,018$ & $0,000^{*}$ & $1 \underline{a}$ fase & 8,15 \\
\hline regulação na formação & Positivo & 52 & 80,81 & & & 2 a fase & 7,85 \\
\hline \multirow[t]{2}{*}{ Ie II } & Igual & 12 & & & & & \\
\hline & Total & 174 & & & & & \\
\hline \multirow{4}{*}{$\begin{array}{l}\text { Autoeficácia na gestão } \\
\text { acadêmica I e II }\end{array}$} & Negativo & 102 & 86,61 & $-2,919$ & $0,004^{*}$ & 1 a fase & 8,46 \\
\hline & Positivo & 65 & 79,91 & & & $2^{\underline{a}}$ fase & 8,20 \\
\hline & Igual & 16 & & & & & \\
\hline & Total & 183 & & & & & \\
\hline Autoeficácia na & Negativo & 96 & 88,74 & $-2,725$ & $0,006^{*}$ & 1 a fase & 8,61 \\
\hline \multirow[t]{4}{*}{ interação social I e II } & Positivo & 69 & 75,01 & & & $2^{\mathrm{a}}$ fase & 8,41 \\
\hline & Igual & 18 & & & & & \\
\hline & Total & 183 & & & & & \\
\hline & Negativo & 96 & 78,44 & $-3,329$ & $0,001^{*}$ & $1 \underline{a}$ fase & 8,08 \\
\hline \multirow{3}{*}{$\begin{array}{l}\text { Autoeficácia na } \\
\text { formação superior I e II }\end{array}$} & Positivo & 55 & 71,75 & & & $2^{\mathrm{a}}$ fase & 7,87 \\
\hline & Igual & 0 & & & & & \\
\hline & Total & 151 & & & & & \\
\hline
\end{tabular}

${ }^{*} p<0,05$ diferença é significante ou $p=0,05$ diferença é significativa.

** Segundo Levin (1987), uma diferença significante mostra que há diferença entre as amostras pesquisadas. Quando $p<0,05$, a diferença é significante, e quando $\mathrm{p}=0,05$, a diferença é significativa, de modo que a diferença significante apresenta menor probabilidade de erro do que a diferença significativa. 
Como pode ser observado na Tabela 2, dentre as dimensões analisadas, a dimensão autoeficácia acadêmica foi a única que não apresentou diferença significativa ( $z$ $=-1,472, p=0,141)$. Nessa dimensão, 90 estudantes obtiveram médias menores (média rank $=83,12$ ) na segunda fase da pesquisa em relação à autoeficácia acadêmica demonstrada na primeira fase, sendo que 72 estudantes apresentaram médias maiores (média rank $=79,47$ ) e 16 apresentaram médias iguais.

Em relação às dimensões que demonstraram diferenças significantes, apresenta-se a dimensão autoeficácia em ações pró-ativas $(z=-3,896, p<0,0001)$. Nessa dimensão, 111 estudantes ingressantes obtiveram médias mais baixas (média rank $=84,19$ ) de autoeficácia em ações pró-ativas na segunda fase, 55 estudantes demonstram médias mais altas (média rank $=82,11$ ) na segunda fase e apenas 9 estudantes apontaram médias de autoeficácia em ações pró-ativas iguais nas duas fases da pesquisa.

Quanto à dimensão autoeficácia na regulação da formação, pôde-se verificar que a hipótese nula também foi rejeitada, pois a diferença mostra-se significante $(z=$ - 4,018; $p<0,0001)$. Dos 174 estudantes ingressantes analisados nessa dimensão, 110 demonstram valores mais baixos (média rank $=81,83$ ) na segunda fase da pesquisa, 52 estudantes indicaram valores mais altos (média rank $=80,81$ ) e 12 apontaram valores iguais nas duas fases da pesquisa.

Ao observar a Tabela 2, percebe-se que a dimensão autoeficácia na gestão acadêmica demonstrou diferença significante entre os resultados da primeira e da segunda fases da pesquisa $(z=-2,919, p=0,004)$. A autoeficácia na gestão acadêmica da segunda fase foi menor para 102 estudantes (média rank $=86,61$ ), maior para 65 estudantes (média rank $=80,81$ ) e igual para 16 estudantes.
Em relação à dimensão autoeficácia na interação social, pode-se pontuar que a diferença entre as duas fases da pesquisa é significante $(z=-2,725, p=0,006)$. Nessa dimensão, 96 estudantes ingressantes apresentaram médias mais baixas (média rank $=88,74)$, na segunda fase da pesquisa 69 estudantes ingressantes apresentaram valores mais altos (média rank $=75,01$ ) e 18 apresentaram valores inalterados.

\section{Discussão}

Ao analisar os resultados expostos, pôde-se verificar uma relação negativa significante para a autoeficácia na formação superior entre a primeira e a segunda fases desta pesquisa. Essa diminuição pode demonstrar que, após as vivências acadêmicas durante o período pesquisado, as percepções dos estudantes se tornaram mais ajustadas ao contexto ambiental bem como as suas capacidades.

Os resultados relativos à dimensão autoeficácia acadêmica parecem indicar que, após vivenciar o cotidiano acadêmico relativo ao processo de aprendizagem como provas, seminários, trabalhos e pesquisas, dentre outras tarefas específicas do estudo e da aprendizagem, o impacto da frequência ao ensino superior não acarretou diferença significativa na percepção da capacidade relativa às tarefas que a compõem. Possivelmente esse resultado possa ser compreendido por meio do entendimento dos conceitos de repertório de ingresso (Astin, 1993) e experiência direta (Bandura, 1997, 2004), isso porque todos os estudantes já vivenciaram experiências educacionais em outros momentos de suas vidas. Desse modo, estudar, fazer anotações, trabalhos e pesquisas, dentre outras estratégias de aprendizagem, não constituem tarefas plenamente desconhecidas, mas passam a ter novos níveis de exigências no ensino superior, os quais podem ser compreendidos 
por meio da aprendizagem vicária. O êxito obtido nas experiências anteriores pôde servir de fonte de autoeficácia para os novos níveis de exigência das tarefas acadêmicas requeridas na graduação. No entanto, a dificuldade do novo nível de exigência poderia explicar a diminuição da média da dimensão autoeficácia acadêmica na segunda fase desta pesquisa, bem como a diferença negativa percebida por 90 estudantes na comparação entre as fases. Apesar de a diferença entre as fases não ter sido significativa, pode-se comentar que a quantidade de estudantes que se percebeu menos capaz em relação às tarefas de estudo e de aprendizagem foi maior, o que mereceu atenção por parte dos envolvidos no processo de ensino.

Em relação à autoeficácia em ações próativas, os resultados parecem indicar que a experiência gerou diminuição significante para a maioria dos estudantes, pois, após um período de frequência na instituição, parte dos estudantes pesquisados percebese menos capaz de utilizar os recursos oferecidos pela instituição. Possivelmente, o aspecto condicional relativo ao trabalho remunerado exercido por 160 estudantes $(84,7 \%)$ contribuiu para que sentissem maiores dificuldades em usufruir as atividades extracurriculares, bem como os outros serviços oferecidos pela instituição. No entanto, 55 estudantes demonstraram alteração positiva (média rank $=82,11$ ) em suas crenças de autoeficácia em ações próativas, revelando maior percepção quanto às suas capacidades analisadas nessa dimensão. Para esses estudantes, possivelmente, as experiências diretas vivenciadas em relação à postura reivindicativa, à participação em atividades extracurriculares, à busca por atualização do conhecimento e por informações sobre as oportunidades, durante o período pesquisado, trouxeram consequências positivas que atuaram como fonte de autoeficácia para as capacidades que compõem essa dimensão. De todo modo, faz-se necessário otimizar o diálogo com os estudantes, a oferta de atividades complementares não obrigatórias, bem como estimular os estudantes a usufruí-las, conscientizando-os sobre a importância das mesmas para a formação multidimensional e para a atualização dos conhecimentos (Astin, 1993).

Pelo resultado obtido na dimensão autoeficácia na regulação superior, pode-se afirmar que a maior parte dos estudantes pesquisados percebe-se menos capaz de planejar, organizar e executar ações que os direcionem ao alcance de suas metas, de formação e acadêmicas após vivenciar as tarefas acadêmicas durante o período pesquisado. Possivelmente, o contexto comentado em relação à dimensão autoeficácia acadêmica também se aplique nessa dimensão, apesar de esta ter apresentado diferença significativa. No início do curso, as capacidades de estabelecer metas, fazer escolhas, planejar e autorregular suas ações não eram percebidas como novidades, pois anteriormente os estudantes já as realizaram, seja na educação básica, seja em ambientes de trabalho. Porém, após a vivência das tarefas multidimensionais que compõem a experiência acadêmica, os estudantes puderam perceber, por meio do feedback recebido, que o nível de exigência das tarefas acadêmicas no ensino superior é mais complexo se comparado à educação básica. O elevado nível de exigência das vivências acadêmicas passa a requerer, com maior intensidade, a capacidade de estabelecer metas, de fazer escolhas, de planejar e autorregular as próprias ações, o que pode contribuir para a diminuição da percepção de tais capacidades bem como das ações proporcionadas por meio dessas. Nesse contexto, somente 52 estudantes demonstraram elevação na crença de autoeficácia na regulação da formação, de modo que a diferença negativa entre 
as duas fases da pesquisa foi significante. Esse resultado mostra ser necessário o desenvolvimento de seminários no primeiro ano, a orientação vocacional, oficinas ou posturas docentes que utilizem diferentes estratégias de ensino aos estudantes, de modo que estes possam ser orientados em relação a como se autorregular e a como planejar sua formação de acordo com as opções das áreas cursadas (Bandura, 2008).

Na dimensão autoeficácia na gestão acadêmica, o resultado parece indicar que, após a vivência acadêmica pertinente ao ensino superior, os estudantes aqui pesquisados se percebem menos capazes em relação às competências de esforço, motivação, respeito aos prazos estabelecidos e ao planejamento das atividades solicitadas pelo curso. Aparentemente, o fato de a autoeficácia na gestão acadêmica ter demonstrado menor intensidade, na segunda fase desta pesquisa, foi possível evidenciar que as estratégias utilizadas para se esforçar, motivar, planejar e respeitar os prazos pelos estudantes nas multidimensionais tarefas compreendidas pelo ensino superior possivelmente exigiram esforço maior do que o suposto e obtiveram retorno menor do que o idealizado, o que contribuiu para a diminuição da autoeficácia na gestão acadêmica. Esse resultado pôde indicar também a falta de apoio e de orientação dos membros responsáveis pelo processo de formação superior para a maioria dos estudantes, que precisa conciliar as tarefas acadêmicas com níveis superiores de exigências, com as atividades de trabalho remunerado e com as demais esferas da vida cotidiana (Bandura, 2008). Entretanto, menor parte dos estudantes $(n=65)$ apresentou elevação da autoeficácia na gestão acadêmica. Tal resultado pode indicar que essa minoria encontrou maior recurso para o estabelecimento das estratégias verificadas por essa dimensão, obtendo êxito em suas experiências diretas. Cabe saber se essa maior percepção de capacidade foi proporcionada pelo repertório de ingresso do estudante, por meio da aprendizagem vicária junto aos pares e ou docentes, ou, ainda, por meio da persuasão social exercida pelos docentes e pelos demais profissionais envolvidos no processo de formação superior.

Em relação à dimensão autoeficácia na interação social, pode-se comentar que a experiência acadêmica se mostrou negativa para a maior parte dos estudantes, com a diminuição da confiança percebida na capacidade de relacionar-se com os colegas e professores em fins acadêmicos e sociais, apesar de essa dimensão ter apresentado as maiores médias descritivas nas duas fases da pesquisa. Desse modo, pode-se comentar que a dinâmica relação triádica, que envolve os aspectos pessoais, comportamentais e ambientais, contribuiu para a diminuição da percepção dos estudantes em relação às suas capacidades de tirar dúvidas, de expor opiniões e de estabelecer bom relacionamento com os docentes e com os colegas. Essa diminuição pode ser explicada por meio do conceito da experiência direta, que pode não ter apresentado boas consequências e ter gerado uma situação desconfortável para os estudantes, bem como pela ausência de feedback desejável, o que poderia indicar pouca contribuição da persuasão social como fonte de autoeficácia (Bandura, 2008). Acrescentase a aprendizagem vicária, por meio da qual se poderia comentar que experiências mal sucedidas em relação a tirar dúvidas ou a expor opiniões em público vivenciadas por outros estudantes contribuíram para a diminuição da crença. Em contrapartida, uma parcela menor dos estudantes $(\mathrm{n}=$ 96) demonstrou elevação da crença de autoeficácia na interação social. Nesse caso, a relação triádica entre os aspectos pessoais, comportamentais dos estudantes e o ambiente institucional foi vivenciada diferentemente por meio dos mesmos 
mecanismos, o que trouxe consequências percebidas como positivas, que contribuíram para a elevação da crença demonstrada pelos estudantes.

\section{Considerações}

Diante do exposto, faz-se necessário questionar se a diminuição da crença de autoeficácia na formação superior, verificada na segunda fase da pesquisa, não a tornou mais próxima da capacidade desses estudantes frente aos desafios propostos pelas vivências acadêmicas. Esse questionamento é permitido, pois a diferença entre as fases foram significantes, de modo que a forte intensidade da autoeficácia na formação superior, verificada na primeira fase da pesquisa $(\mathrm{m}=8,08 ; \mathrm{dp}=0,984)$, pode ter aproveitado o sucesso proporcionado pelo ingresso ao ensino superior e, assim, ter apresentado um julgamento superestimado da crença de eficácia na formação superior, criado com base em uma ideia construída por meio da expectativa, e não por meio de experiência vivenciada. Nesse caso, a diminuição da crença tornaria a percepção dos estudantes pesquisados mais próxima de suas reais capacidades, que decorrem do esforço, dedicação, autorreflexão e autorregulação diante das exigências das vivências acadêmicas. De fato, isso pode ter acontecido, contudo, deve-se considerar que, segundo a teoria social cognitiva, o êxito obtido com a conquista da meta pôde servir de fonte de autoeficácia na formação superior, constituindo uma fonte vinda da experiência direta, que é entendida como a fonte de eficácia mais forte dentre as demais fontes (Bandura, 1997, 2004).

Nesse contexto, é importante lembrar que a crença de autoeficácia na formação superior é determinante para o rendimento acadêmico (Dias \& Azevedo, 2001). Assim, ressalta-se que as diferenças negativas e significantes constatadas nesta pesquisa merecem ser criteriosamente consideradas pelos responsáveis pelo processo de formação superior, pois pode indicar diminuição no desempenho dos estudantes. Apesar de se reconhecer que essa diminuição observada pode ter tornado a percepção da autoeficácia na formação superior mais próxima da capacidade dos estudantes, seria importante que as vivências acadêmicas pertinentes à frequência ao ensino universitário pudessem contribuir para o fortalecimento da autoeficácia na formação superior, o que poderia colaborar tanto para o desenvolvimento multidimensional dos estudantes como para o rendimento acadêmico e para a aprendizagem autorregulada. Isso ocorre porque, segundo Bandura (1997), apresentar uma percepção de autoeficácia forte, um pouco acima do real nível de capacidade, é ideal para estimular a ação pessoal em busca da realização de metas. Com um forte julgamento da autoeficácia na formação superior, o estudante provavelmente consideraria uma tarefa complexa um desafio a ser conquistado, e não algo a ser evitado, fato que pode contribuir para o seu envolvimento e comprometimento na graduação.

Para tanto, a postura docente que permita um relacionamento com os estudantes permeado pelo diálogo coloca-se como fundamental para a qualidade da construção da autoeficácia na formação superior dos ingressantes. O modo de o docente se comunicar com os estudantes constitui importante fonte persuasiva de autoeficácia na formação superior (Byer, 2001), desde que evidencie as falhas e as conquistas realizadas pelos alunos, orientando-os clara e objetivamente em relação às tarefas acadêmicas, sempre com respeito pela pessoa com a qual está lidando. Nesse sentido, por meio desta pesquisa, destacamse as necessidades de desenvolver ações 
pedagógicas que visem à otimização das ações docentes, com foco na relação interpessoal e na emissão de feedback aos estudantes, bem como no desenvolvimento da autoeficácia na formação superior, necessária ao estudo, à aprendizagem, ao desempenho e ao desenvolvimento dos estudantes.

Ao ampliar o foco para além da sala de aula, o que inclui todo o processo de formação, seria necessário que as políticas de gestão, os projetos pedagógicos, os coordenadores de curso e os serviços de apoio aos estudantes reconhecessem e compreendessem o papel da crença de autoeficácia na formação superior para o desenvolvimento multidimensional do estudante. Aproveitar o bom momento da autoeficácia na formação superior obtida com o êxito no ingresso e estimulá-la em termos de intensidade e de magnitude para que possa subsidiar a utilização de estratégias metacognitivas, necessárias para a aprendizagem autorregulada requerida para a construção e a aplicação de novos conhecimentos e para acompanhar o ritmo em que as informações são produzidas nesta era, constituem estratégias valiosas para a integração ao ensino superior e para a formação multidimensional dos alunos. Nesse sentido, ressalta a necessidade de se pensar nos modelos educacionais diversamente oferecidos sob uma ótica que privilegie o estímulo à autoeficácia na formação superior como mediadora do desempenho e da formação multidimensional do estudante.

Nesse contexto, pode-se apontar a viabilidade de se realizar intervenções que visem à promoção da autoeficácia na formação superior, atuando nas fontes da mesma, como a experiência direta, a aprendizagem vicária, a persuasão social e o estado físicoemocional. Para tanto, o serviço de apoio ao estudante poderia realizar oficinas que visassem à promoção de orientações sobre estratégias de estudo e de autorregulação da aprendizagem, dentre outras, que poderiam contribuir para a construção da crença de eficácia na formação superior dos estudantes. Além disso, poderiam ser realizadas ações que visassem a estimular o convívio social, dentro e fora da instituição, como atividades complementares não obrigatórias, eventos culturais e desportivos, que poderiam otimizar a autoeficácia na interação social, contribuindo para o processo de formação superior.

A partir das informações obtidas por meio desta pesquisa, pôde-se perceber a importância da autoeficácia na formação superior. Reconhece-se que a especificidade da amostra limita a generalização dos resultados e que o período no qual os estudantes foram acompanhados não possibilita compreensão sobre a totalidade do possível dinamismo da crença de autoeficácia ao longo do curso. No entanto, esses resultados podem contribuir para outras pesquisas a serem realizadas, bem como para sugerir a necessidade de novas pesquisas, visando-se obter informações sobre as fontes das mudanças ocorridas na autoeficácia na formação superior durante a frequência ao ensino superior, sobre análise qualitativa em relação às mudanças da autoeficácia na formação superior, sobre a relação da autoeficácia na formação superior e a aprendizagem autorregulada e sobre o papel do docente como fonte de autoeficácia na formação superior, dentre outras. Pelo exposto, acredita-se que esta pesquisa possa contribuir para ampliar o conhecimento sobre o estudante, auxiliando o entendimento sobre os constructos autorreferentes relacionados à permanência, ao sucesso acadêmico e ao desenvolvimento multidimensional do estudante. 


\section{Daniela Couto Guerreiro-Casanova}

Mestre em Educação pela Universidade Estadual de Campinas, doutoranda em Educação, Universidade Estadual de Campinas, São Paulo - SP - Brasil.

E-mail: danielaguerreiro@yahoo.com.br

\section{Soely Aparecida Jorge Polydoro}

Doutora em Educação pela Universidade Estadual de Campinas, docente da Faculdade de Educação da Universidade Estadual de Campinas, São Paulo - SP - Brasil.

E-mail.: polydoro@sigmanet.com.br

Endereço para envio de correspondência:

R. Jacques Felix, 278 apto 81 Vila Nova Conceição, São Paulo - SP - Brasil CEP 04509-001 
Albiero-Walton, J. (2003). Self-efficacy gender in college students with disabilities. Information analyses. Recuperado em 11 julho de 2006, de http://www.eric.ed.gov.

Astin, A. W. (1993). What matters in college? Four cricial years revisited. San Francisco: Jossey-Bass.

Bandura, A., \& Cervone, D. (1983). Self-evaluative and selfefficacy mechanisms governing the motivational effects of goal systems. Journal of Personality and Social Psychology, 45, 1017-1028.

Bandura, A., \& Cervone, D. (1986). Differential engagement of self-reactive influences in cognitive motivation. Organizational Behavior and Human Decision Processes, 38, 92-113.

Bandura, A. (1997). Self-efficacy, the exercise of control. New York: Freeman and Company.

Bandura, A. (2004). Swimming against the mainstream: The early years from chilly tributary to transformative mainstream. Behaviour Research and Therapy, 42, 613-630.

Bandura, A. (2008). A evolução da teoria social cognitiva. In A. Bandura, R. G. Azzi, \& S. A. Polydoro (Orgs.), Teoria social cognitiva: conceitos básicos (pp.15-65). Porto Alegre: Artmed.

Byer, J. L. (2001). The effects of college students' perceptions of teaching and learning on academic self-efficacy and course evaluations. In 30 Annual Meeting of the Mid-South Educational Research Association. Recuperado em 13 de setembro de 2005, de http:www.eric.ed. gov.

Cole, J. S., \& Denzine, G. M. (2004). I'm not doing as well in this class as I'd like to: Exploring achievement motivation and personality. Recuperado em 7 de setembro de 2005, de http:www.eric.ed.gov .

Dias, G. F., \& Azevedo, M. (2001). Desenvolvimento psicológico, atitudes em relação ao estudo e sucesso acadêmico. In Fases on-line: factores de sucesso/insucesso do ensino superior. Recuperado em 14 de maio, 2005, de _http://www.ualg.pt/ OPQE/fases/.
Hirose, E. I., Wadas, S., \& Watanabe, H. (1999). Effects of selfefficacy on adjustment to college. Japanese Psychological Research, 4(3), 163-172.

Jakubowski, T. G., \& Dembo, M. H. (2004). The relationship pf self-efficacy, identity style and stage of change with academic self-regulation. Recuperado em 7 setembro de 2005, de http:www.eric.ed.gov.

Lent, R. W., Taveira, M. C., Sheu, H. B., \& Singley, D. (2009). Social cognitive predictors of academic adjustment and life satisfaction in portuguese college students: A longitudinal analysis. Journal of Vocational Behavior, 79(2), 190-198.

Levin, J. (1987). Estatística aplicada a ciências humanas. (2a ed., S. F. Costa, trad.). São Paulo: Harbra

Oliveira, A. L., \& Simões, A. (2001).Validação do questionário de autoeficácia para a aprendizagem autodirigida: sua relevância na facilitação da aprendizagem dos estudantes do ensino superior. Revista Portuguesa de Pedagogia, 35(1), 171-190.

Pascarella, E.T., \& Terenzini, P.T. (2005). How college affects students: A third decade of research (Vol. 2, 2a ed., pp. 571626). San Francisco: Jossey-Bass.

Polydoro, S.A.J. \& Guerreiro-Casanova, D.C. (2010). Escala de Autoeficácia na Formação Superior: construção e estudo de validação. Avaliação Psicológica, 9(2), 267-278.

Stallworth-Clark, R., Nolen, M. T., Warketing, R., \& Scott, J. S. (2000). College studentes' academic performance: The interaction of strategy engagement, content and context. Trabalho apresentado no American Educational Research Association Annual Meeting. Recuperado em 1 de julho de 2006, de http: www.eric.ed.gov.

Zajacova, A., Lynch, S. M., \& Espenshade, T. J. (2005). Selfefficacy, stress, and academic sucess in college. Research in higher education, 46(6), 677-706. Recuperado em 19 setembro de 2006, de http: www.eric.ed.gov. 